\title{
An Investigation of the Recent Linkages of Consumer Prices in Japan
}

\author{
Chikashi Tsuji ${ }^{1}$ \\ ${ }^{1}$ Faculty of Economics, Chuo University, Tokyo, Japan \\ Correspondence: Chikashi Tsuji, Professor, Faculty of Economics, Chuo University, 742-1 Higashinakano \\ Hachioji-shi, Tokyo 192-0393, Japan. Tel: 81-42-674-2211. E-mail: mail_sec_low@minos.ocn.ne.jp
}

Received: September 27, 2015

Accepted: October 16, $2015 \quad$ Online Published: November 30, 2015

doi:10.5430/ijfr.v7n1p9

URL: http://dx.doi.org/10.5430/ijfr.v7n1p9

\begin{abstract}
This paper tests the time-series linkages of several consumer price indices (CPIs) in Japan by using the vector error correction model (VECM) approach. Our empirical tests demonstrate the interesting findings as follows. First, we clarify that 1) all the cointegrating equations of our six VECM models are statistically significant strongly. Hence our results indicate that our six combinations of the time-series of Japanese CPIs examined in this study are all much strongly cointegrated. This therefore suggests that for capturing the time-series connections of the Japanese CPIs, the VECM approach is significantly effective. Further, we also reveal that 2) as far as judging by the results of our impulse response analyses, it is understood that, in our analyzing sample period, the Japanese core CPI is not so strongly influenced by the Japanese CPI of energy, telecommunication expenses, insurance and medical expenses, or industrial goods. 3) Furthermore, our analyses of impulse responses also demonstrate that the Japanese core CPI is largely affected by both the CPIs of services and nondurable goods for Japan.
\end{abstract}

Keywords: cointegration, consumer prices, core CPI, VECM

\section{Introduction}

There are several important measures of prices such as the headline consumer price index (CPI) and core CPI. The evolution of consumer prices of specific categories such as energy prices and food prices is also important for entire consumer prices. How are these different consumer prices related to each other? In conducting monetary policies, the core CPI is the biggest concern for central bankers in Japan. How then do the consumer prices of specific categories affect the Japanese core CPI? Based on the above motivation, this paper tests the effects of Japanese consumer prices of energy, telecommunication expenses, insurance and medical expenses, services, industrial goods, and nondurable goods on the Japanese core CPI by employing the bivariate-vector error correction model (VECM) analyses.

Our investigations firstly reveal that 1) all the cointegrating equations of our six VECM models are statistically significant strongly. Thus our empirical results mean that our six combinations of the time-series of Japanese CPIs studied in this paper are all much strongly cointegrated. This therefore suggests that for capturing the time-series connections of the Japanese CPIs, the VECM approach is significantly effective. Second, we further present that 2) as far as judging by the results of our impulse response analyses, in our analyzing sample period, the Japanese core $\mathrm{CPI}$ is not so strongly influenced by the Japanese CPI of energy, telecommunication expenses, insurance and medical expenses, or industrial goods. 3) Moreover, our analyses of impulse responses demonstrate that the Japanese core CPI is largely affected by both the CPIs of services and nondurable goods for Japan.

Regarding the rest of this paper, Section 2 reviews the past related studies, Section 3 explains our data, and Section 4 documents our models and methodology. Section 5 explains our results and Section 6 provides our interpretations and conclusions.

\section{Literature Review}

This section concisely reviews existing literature in connection with inflation. Regarding CPIs, many past research investigated inflation forecasting and recent research seems to use several different measures of price inflation in their empirical studies. First, Juselius (1992) empirically examined the price determination in Denmark by using three kinds of macroeconomic theoretical explanations. Stock and Watson (2007) investigated whether the modeling of the US price inflation had become more difficult than before. The main finding of their study was that an unobserved component trend-cycle model well described the univariate inflation process. 
In addition, Bodenstein et al. (2008) examined the alternative monetary rules' performances in response to a shock to energy supply by employing the optimal rule that maximizes household welfare. Their key finding was that the optimal response to an adverse shock in energy supply led to a persistent rise in headline and core inflation. Bullard (2011) presented an interesting debate with regard to the appropriateness of using headline and core measures of inflation expectations in executing monetary policies. Manzan and Zerom (2013) revealed that several macroeconomic indicators, such as term spreads, unemployment rates, and housing starts, exhibited significant out-of-sample predictability for the US core inflation distribution. Moreover, Arora et al. (2013) found the periods in which the headline personal consumption expenditure (PCE) price index was highly volatile in comparison with the core PCE.

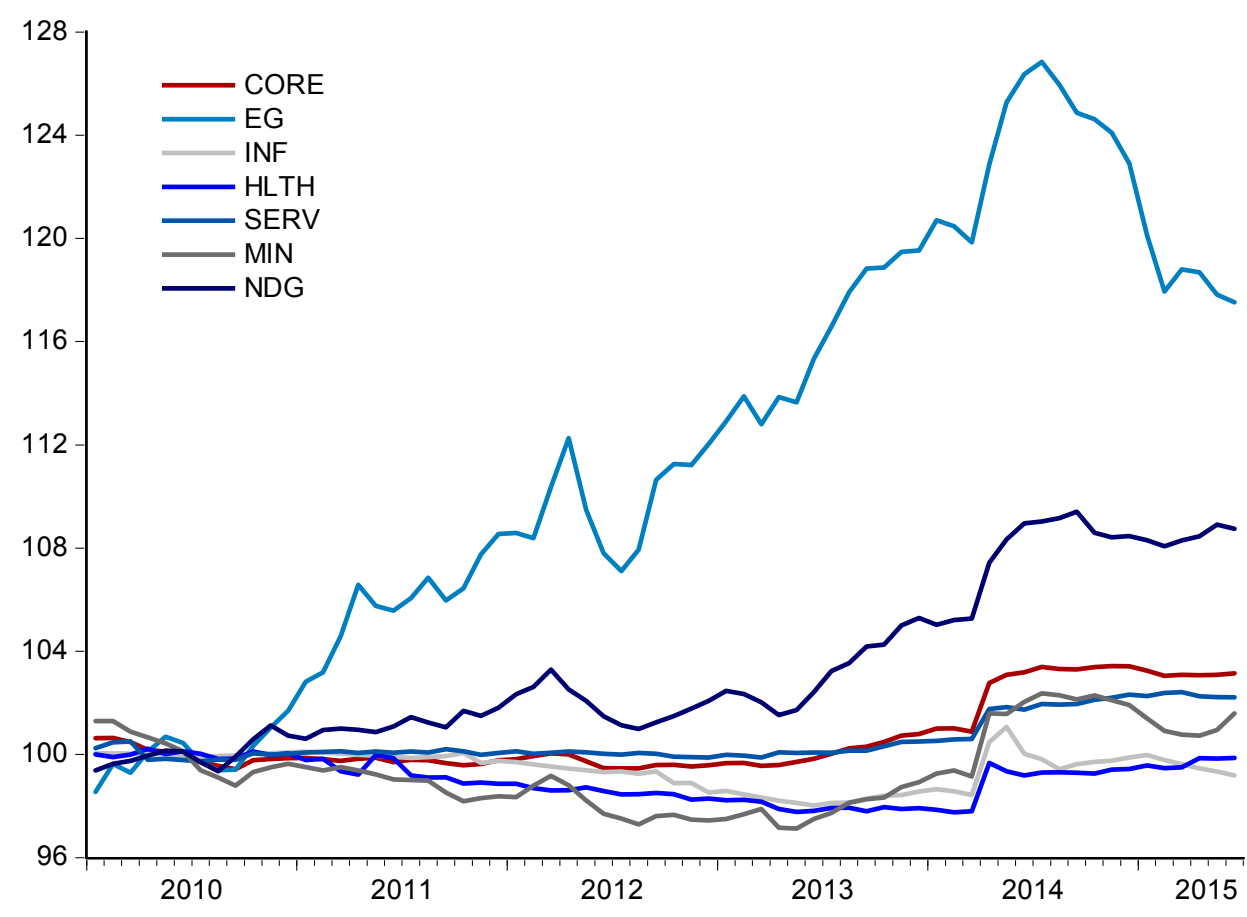

Figure 1. Time-series evolution of the Japanese CPIs: For the period from January 2010 to June 2015

\section{Data}

This section documents our data we explore in this study. This research uses seven sorts of Japanese consumer price indices. More concretely, 1) CORE denotes the CPI of all items excluding food for Japan (so-called the core CPI for Japan); 2) EG means the CPI of energy for Japan; 3) INF denotes the CPI of telecommunication expenses for Japan; and 4) HLTH denotes the CPI of insurance and medical expenses for Japan. Moreover, 5) SERV represents the CPI of services for Japan; 6) MIN denotes the CPI of industrial goods for Japan; and 7) NDG means the CPI of nondurable goods for Japan. The above seven monthly time-series are all seasonally-adjusted and our analyzing sample period spans May 2011 to June 2015. All data for our investigations are from the QUICK Corp.

The time-series changes for the above seven Japanese CPIs are shown in Figure 1. Further, Table 1 exhibits their descriptive statistics. As Figure 1 shows, the CPI of energy (EG) and the CPI of nondurable goods (NDG) continuously increased during the sample period except for the period after around 2014. On the other hand, the CPI of all items excluding food (CORE) only slightly increased around 2014. Further, from Figure 1, we also understand that the CPI of telecommunication expenses (INF), the CPI of insurance and medical expenses (HLTH), the CPI of services (SERV), and the CPI of industrial goods (MIN) were generally under the CORE after around 2011.

Moreover, regarding the Japanese CPIs, Table 1 indicates that the standard deviation values of INF, HLTH and SERV display lower values whilst the standard deviations of EG and NDG are clearly higher. We also understand that EG and NDG are more volatile than CORE whilst INF, HLTH and SERV are less volatile than CORE. These data characteristics are consistent with the time-series CPI trends seen in Figure 1. 
Table 1. Descriptive statistics of seven kinds of Japanese CPIs: For the period from May 2011 to June 2015

\begin{tabular}{|c|c|c|c|c|}
\hline & CORE & EG & & INF \\
\hline Mean & 100.9064 & 115.1879 & & 99.2521 \\
\hline Median & 100.0100 & 114.6090 & & 99.4073 \\
\hline Maximum & 103.4275 & 126.8399 & & 101.0594 \\
\hline Minimum & 99.4559 & 105.5731 & & 98.0234 \\
\hline Standard deviation & 1.5647 & 6.5211 & & 0.7130 \\
\hline Skewness & 0.7133 & 0.1370 & & -0.0683 \\
\hline \multirow[t]{2}{*}{ Kurtosis } & 1.6983 & 1.7906 & & 2.2950 \\
\hline & HLTH & & SERV & \\
\hline Mean & 98.7499 & & 100.7163 & \\
\hline Median & 98.7043 & & 100.1264 & \\
\hline Maximum & 99.9674 & & 102.4116 & \\
\hline Minimum & 97.7555 & & 99.8787 & \\
\hline Standard deviation & 0.6918 & & 0.9377 & \\
\hline Skewness & 0.0905 & & 0.8359 & \\
\hline \multirow[t]{2}{*}{ Kurtosis } & 1.7401 & & 1.8735 & \\
\hline & MIN & & NDG & \\
\hline Mean & 99.2586 & & 104.3133 & \\
\hline Median & 98.7929 & & 102.9236 & \\
\hline Maximum & 102.3630 & & 109.4068 & \\
\hline Minimum & 97.1293 & & 100.8591 & \\
\hline Standard deviation & 1.7039 & & 3.0539 & \\
\hline Skewness & 0.6227 & & 0.5115 & \\
\hline Kurtosis & 1.9383 & & 1.6016 & \\
\hline
\end{tabular}

Notes: This table exhibits the descriptive statistics with regard to the variables analyzed in this study. Specifically, CORE denotes the CPI of all items excluding food for Japan; EG means the CPI of energy for Japan; INF denotes the CPI of telecommunication expenses for Japan; and HLTH denotes the CPI of insurance and medical expenses for Japan. Moreover, SERV represents the CPI of services for Japan; MIN denotes the CPI of industrial goods for Japan; and NDG means the CPI of nondurable goods for Japan. Samples are monthly and our analyzing sample period spans May 2011 to June 2015.

\section{Testing Methodology}

This section introduces the models for our empirical tests. For examining the effects of the above mentioned six CPIs of EG, INF, HLTH, SERV, MIN, and NDG on the core Japanese CPI, CORE, we test six sorts of VECMs. Namely, we examine the bivariate-VECMs of 1) CORE and EG; 2) CORE and INF; 3) CORE and HLTH; 4) CORE and SERV; 5) CORE and MIN; and 6) CORE and NDG. Our model determinations are in accordance with the Johansen's $(1991 ; 1995)$ tests of cointegration and all our six models can be written as the following two equations (1) and (2):

$$
\begin{aligned}
\Delta z_{t} & =\kappa_{1} C E+\sum_{h=1}^{p} \xi_{1, h} \Delta z_{t-h}+\sum_{j=1}^{q} \phi_{1, j} \Delta x_{t-j}+\tau_{1, t}, \\
\Delta x_{t} & =\kappa_{2} C E+\sum_{r=1}^{p} \xi_{2, r} \Delta z_{t-r}+\sum_{s=1}^{q} \phi_{2, s} \Delta x_{t-s}+\tau_{2, t} .
\end{aligned}
$$

In the above equations, $z$ means the variable CORE, $x$ means one of the other six Japaense CPIs, and $\Delta z$ and $\Delta x$ show the first differences in terms of the variables $z$ and $x$, respectively.

With regard to two VECMs of CORE and MIN and CORE and NDG, the cointegrating equation (CE) in each model includes an intercept as $C E=z_{t-1}+\lambda x_{t-1}+\eta$ while other four VECMs contain no intercept as $C E=z_{t-1}+\lambda x_{t-1}$. In the above models, $p$ and $q$ mean the model lag orders. After the determinations, our six models for the Japanese CPIs are specified as 1) $\operatorname{VECM}(1,1)$ for $\operatorname{CORE}$ and $\operatorname{EG}$; 2) $\operatorname{VECM}(6,6)$ for $\operatorname{CORE}$ and INF; 3) $\operatorname{VECM}(3,3)$ for CORE and HLTH; 4) $\operatorname{VECM}(6,6)$ for CORE and SERV; 5) $\operatorname{VECM}(7,7)$ for CORE and MIN; and 6) VECM $(4,4)$ for CORE and NDG. 
Table 2. Estimation results of the VECMs: The effects of specific consumer prices on the core CPI: Six Japanese cases for the period from May 2011 to June 2015

\begin{tabular}{|c|c|c|c|c|c|}
\hline \multicolumn{3}{|c|}{ Panel A. CORE and EG } & \multicolumn{3}{|c|}{ Panel B. CORE and INF } \\
\hline \multicolumn{3}{|c|}{ Cointegrating equation } & \multicolumn{3}{|c|}{ Cointegrating equation } \\
\hline & \multicolumn{2}{|l|}{ Coefficients } & & \multicolumn{2}{|l|}{ Coefficients } \\
\hline $\operatorname{CORE}(-1)$ & \multicolumn{2}{|l|}{1.0000} & $\operatorname{CORE}(-1)$ & \multicolumn{2}{|l|}{1.0000} \\
\hline $\mathrm{EG}(-1)$ & \multicolumn{2}{|l|}{$-0.8850 * * *$} & $\operatorname{INF}(-1)$ & \multicolumn{2}{|l|}{$-1.8834 * * *$} \\
\hline$p$-value & \multicolumn{2}{|l|}{0.0000} & $p$-value & \multicolumn{2}{|l|}{0.0000} \\
\hline \multicolumn{3}{|c|}{ Error corrections } & \multicolumn{3}{|c|}{ Error corrections } \\
\hline & \multicolumn{2}{|l|}{ Variables } & & \multicolumn{2}{|l|}{ Variables } \\
\hline & $\triangle \mathrm{CORE}$ & $\Delta \mathrm{EG}$ & & $\Delta \mathrm{CORE}$ & $\Delta \mathrm{INF}$ \\
\hline & Coefficients & Coefficients & & Coefficients & Coefficients \\
\hline $\mathrm{CE}$ & -0.0144 & 0.0639 & $\mathrm{CE}$ & -0.0009 & 0.0005 \\
\hline$p$-value & 0.1600 & 0.1091 & $p$-value & 0.3290 & 0.6698 \\
\hline$\Delta \operatorname{CORE}(-1)$ & 0.0451 & $1.2958^{*}$ & $\Delta \operatorname{CORE}(-1)$ & 0.0051 & 0.0766 \\
\hline$p$-value & 0.8142 & 0.0875 & $p$-value & 0.9889 & 0.8535 \\
\hline$\Delta \mathrm{EG}(-1)$ & 0.0143 & 0.2184 & $\Delta \operatorname{CORE}(-2)$ & 0.0294 & -0.5021 \\
\hline \multirow[t]{21}{*}{$p$-value } & \multirow[t]{21}{*}{0.7384} & \multirow[t]{21}{*}{0.1949} & $p$-value & 0.9331 & 0.2062 \\
\hline & & & $\Delta \operatorname{CORE}(-3)$ & 0.1059 & 0.3028 \\
\hline & & & $p$-value & 0.7742 & 0.4664 \\
\hline & & & $\Delta \operatorname{CORE}(-4)$ & -0.3684 & -0.3519 \\
\hline & & & $p$-value & 0.3139 & 0.3904 \\
\hline & & & $\Delta \operatorname{CORE}(-5)$ & 0.2787 & 0.5095 \\
\hline & & & $p$-value & 0.4078 & 0.1809 \\
\hline & & & $\Delta \operatorname{CORE}(-6)$ & -0.0202 & 0.2845 \\
\hline & & & $p$-value & 0.9543 & 0.4740 \\
\hline & & & $\Delta \operatorname{INF}(-1)$ & 0.1316 & 0.1430 \\
\hline & & & $p$-value & 0.6882 & 0.6976 \\
\hline & & & $\Delta \mathrm{INF}(-2)$ & -0.0844 & -0.0517 \\
\hline & & & $p$-value & 0.7803 & 0.8790 \\
\hline & & & $\Delta \mathrm{INF}(-3)$ & 0.1167 & -0.1360 \\
\hline & & & $p$-value & 0.6924 & 0.6813 \\
\hline & & & $\Delta \mathrm{INF}(-4)$ & 0.2089 & 0.2176 \\
\hline & & & $p$-value & 0.4656 & 0.4979 \\
\hline & & & $\Delta \mathrm{INF}(-5)$ & -0.1536 & -0.2661 \\
\hline & & & $p$-value & 0.5241 & 0.3272 \\
\hline & & & $\Delta \mathrm{INF}(-6)$ & 0.1591 & -0.1198 \\
\hline & & & $p$-value & 0.5164 & 0.6628 \\
\hline AIC & 0.5008 & 3.2188 & AIC & 0.9936 & 1.2242 \\
\hline $\mathrm{SC}$ & 0.6178 & 3.3357 & $\mathrm{SC}$ & 1.5260 & 1.7567 \\
\hline Panel C. COI & ALTH & & Panel D. COP & d SERV & \\
\hline Cointegrating & tion & & Cointegrating & tion & \\
\hline
\end{tabular}




\begin{tabular}{|c|c|c|c|c|c|}
\hline $\operatorname{CORE}(-1)$ & \multicolumn{2}{|l|}{1.0000} & $\operatorname{CORE}(-1)$ & \multicolumn{2}{|l|}{1.0000} \\
\hline $\operatorname{HLTH}(-1)$ & \multicolumn{2}{|l|}{$-1.0255 * * *$} & $\operatorname{SERV}(-1)$ & \multicolumn{2}{|l|}{$-0.9985^{* * *}$} \\
\hline$p$-value & \multicolumn{2}{|l|}{0.0000} & $p$-value & \multicolumn{2}{|l|}{0.0000} \\
\hline \multicolumn{3}{|c|}{ Error corrections } & \multicolumn{3}{|c|}{ Error corrections } \\
\hline & \multicolumn{2}{|l|}{ Variables } & & \multicolumn{2}{|l|}{ Variables } \\
\hline & $\triangle \mathrm{CORE}$ & $\Delta \mathrm{HLTH}$ & & $\Delta \mathrm{CORE}$ & $\triangle \Delta$ SERV \\
\hline & Coefficients & Coefficients & & Coefficients & Coefficients \\
\hline$\overline{\mathrm{CE}}$ & 0.0095 & $0.0751^{*}$ & $\mathrm{CE}$ & -0.1061 & 0.0385 \\
\hline$p$-value & 0.8393 & 0.0962 & $p$-value & 0.4999 & 0.6891 \\
\hline$\Delta \operatorname{CORE}(-1)$ & 0.1274 & -0.2014 & $\Delta \operatorname{CORE}(-1)$ & -0.0597 & -0.1209 \\
\hline$p$-value & 0.6959 & 0.5165 & $p$-value & 0.8867 & 0.6382 \\
\hline$\Delta \operatorname{CORE}(-2)$ & 0.0439 & 0.1142 & $\Delta \operatorname{CORE}(-2)$ & 0.0073 & 0.0074 \\
\hline$p$-value & 0.8811 & 0.6825 & $p$-value & 0.9862 & 0.9772 \\
\hline$\Delta \operatorname{CORE}(-3)$ & 0.2789 & 0.0854 & $\Delta \operatorname{CORE}(-3)$ & 0.3331 & 0.2581 \\
\hline$p$-value & 0.2953 & 0.7347 & $p$-value & 0.4081 & 0.2965 \\
\hline$\Delta \operatorname{HLTH}(-1)$ & 0.0068 & -0.0166 & $\Delta \operatorname{CORE}(-4)$ & -0.2108 & 0.0381 \\
\hline$p$-value & 0.9843 & 0.9594 & $p$-value & 0.6072 & 0.8792 \\
\hline$\Delta \operatorname{HLTH}(-2)$ & -0.0437 & -0.2616 & $\Delta \operatorname{CORE}(-5)$ & -0.0593 & 0.0648 \\
\hline$p$-value & 0.8709 & 0.3094 & $p$-value & 0.8875 & 0.8006 \\
\hline$\Delta \operatorname{HLTH}(-3)$ & -0.1517 & -0.1269 & $\Delta \operatorname{CORE}(-6)$ & -0.2097 & 0.0684 \\
\hline \multirow[t]{13}{*}{$p$-value } & \multirow[t]{13}{*}{0.5410} & \multirow[t]{13}{*}{0.5902} & $p$-value & 0.6123 & 0.7869 \\
\hline & & & $\Delta \operatorname{SERV}(-1)$ & 0.4642 & 0.1733 \\
\hline & & & $p$-value & 0.5147 & 0.6906 \\
\hline & & & $\Delta \operatorname{SERV}(-2)$ & 0.2139 & -0.1099 \\
\hline & & & $p$-value & 0.7593 & 0.7970 \\
\hline & & & $\Delta \operatorname{SERV}(-3)$ & -0.1113 & -0.1997 \\
\hline & & & $p$-value & 0.8745 & 0.6440 \\
\hline & & & $\Delta \operatorname{SERV}(-4)$ & 0.2603 & -0.1698 \\
\hline & & & $p$-value & 0.7228 & 0.7056 \\
\hline & & & $\Delta \operatorname{SERV}(-5)$ & 0.3495 & -0.0310 \\
\hline & & & $p$-value & 0.6144 & 0.9418 \\
\hline & & & $\triangle \operatorname{SERV}(-6)$ & 0.7148 & 0.0098 \\
\hline & & & $p$-value & 0.2878 & 0.9808 \\
\hline AIC & 0.7184 & 0.6171 & AIC & 1.0040 & 0.0228 \\
\hline $\mathrm{SC}$ & 0.9966 & 0.8954 & $\mathrm{SC}$ & 1.5365 & 0.5553 \\
\hline \multicolumn{3}{|c|}{ Panel E. CORE and MIN } & \multicolumn{3}{|c|}{ Panel F. CORE and NDG } \\
\hline \multicolumn{3}{|c|}{ Cointegrating equation } & \multicolumn{3}{|c|}{ Cointegrating equation } \\
\hline & \multicolumn{2}{|l|}{ Coefficients } & & \multicolumn{2}{|l|}{ Coefficients } \\
\hline $\operatorname{CORE}(-1)$ & \multicolumn{2}{|l|}{1.0000} & $\operatorname{CORE}(-1)$ & \multicolumn{2}{|l|}{1.0000} \\
\hline $\operatorname{MIN}(-1)$ & \multicolumn{2}{|l|}{$-1.2653 * * *$} & $\operatorname{NDG}(-1)$ & \multicolumn{2}{|l|}{$-0.5404 * * *$} \\
\hline$p$-value & \multicolumn{2}{|l|}{0.0000} & $p$-value & \multicolumn{2}{|l|}{0.0000} \\
\hline Intercept & 22.3762 & & Intercept & $-44.5740 * * *$ & \\
\hline$p$-value & 0.3598 & & $p$-value & 0.0000 & \\
\hline
\end{tabular}




\begin{tabular}{|c|c|c|c|c|c|}
\hline \multirow[t]{3}{*}{ Error corrections } & \multicolumn{5}{|c|}{ Error corrections } \\
\hline & Variables & & & Variables & \\
\hline & $\triangle \mathrm{CORE}$ & $\Delta \mathrm{MIN}$ & & $\Delta \mathrm{CORE}$ & $\Delta \mathrm{NDG}$ \\
\hline & Coefficients & Coefficients & & Coefficients & Coefficients \\
\hline $\mathrm{CE}$ & -0.0260 & 0.0712 & $\mathrm{CE}$ & $-0.6024 * * *$ & -0.1060 \\
\hline$p$-value & 0.6448 & 0.4157 & $p$-value & 0.0094 & 0.7992 \\
\hline$\Delta \operatorname{CORE}(-1)$ & 0.2832 & 0.2886 & $\Delta \operatorname{CORE}(-1)$ & 0.2352 & 0.3530 \\
\hline$p$-value & 0.5821 & 0.7162 & $p$-value & 0.3212 & 0.4257 \\
\hline$\Delta \operatorname{CORE}(-2)$ & -0.3399 & 0.6122 & $\Delta \operatorname{CORE}(-2)$ & 0.0353 & 0.1445 \\
\hline$p$-value & 0.5017 & 0.4339 & $p$-value & 0.8789 & 0.7393 \\
\hline$\Delta \operatorname{CORE}(-3)$ & 0.2391 & 0.7688 & $\Delta \operatorname{CORE}(-3)$ & $0.4285^{*}$ & 0.2270 \\
\hline$p$-value & 0.6907 & 0.4091 & $p$-value & 0.0580 & 0.5842 \\
\hline$\Delta \operatorname{CORE}(-4)$ & -0.3101 & 0.3359 & $\triangle \mathrm{CORE}(-4)$ & 0.0364 & 0.1358 \\
\hline$p$-value & 0.5814 & 0.6987 & $p$-value & 0.8719 & 0.7482 \\
\hline$\Delta \operatorname{CORE}(-5)$ & -0.2096 & 0.3759 & $\Delta \mathrm{NDG}(-1)$ & -0.0246 & 0.1699 \\
\hline$p$-value & 0.7253 & 0.6834 & $p$-value & 0.8654 & 0.5333 \\
\hline$\Delta \mathrm{CORE}(-6)$ & 0.4109 & 0.9858 & $\Delta \mathrm{NDG}(-2)$ & -0.0227 & 0.1039 \\
\hline$p$-value & 0.4151 & 0.2085 & $p$-value & 0.8748 & 0.7004 \\
\hline$\Delta \operatorname{CORE}(-7)$ & -0.2822 & 0.3254 & $\Delta \mathrm{NDG}(-3)$ & $-0.3347 * *$ & -0.2474 \\
\hline$p$-value & 0.5783 & 0.6778 & $p$-value & 0.0176 & 0.3348 \\
\hline$\Delta \mathrm{MIN}(-1)$ & -0.0884 & -0.0775 & $\Delta \mathrm{NDG}(-4)$ & -0.0610 & -0.0972 \\
\hline$p$-value & 0.7859 & 0.8774 & $p$-value & 0.6617 & 0.7096 \\
\hline$\Delta \mathrm{MIN}(-2)$ & 0.2278 & -0.1818 & & & \\
\hline$p$-value & 0.4769 & 0.7124 & & & \\
\hline$\Delta \mathrm{MIN}(-3)$ & -0.0633 & -0.3550 & & & \\
\hline$p$-value & 0.8577 & 0.5159 & & & \\
\hline$\Delta \mathrm{MIN}(-4)$ & 0.1082 & -0.2956 & & & \\
\hline$p$-value & 0.7478 & 0.5699 & & & \\
\hline$\Delta \mathrm{MIN}(-5)$ & 0.2157 & -0.1664 & & & \\
\hline$p$-value & 0.5410 & 0.7596 & & & \\
\hline$\Delta \mathrm{MIN}(-6)$ & -0.2638 & -0.5130 & & & \\
\hline$p$-value & 0.3854 & 0.2758 & & & \\
\hline$\Delta \operatorname{MIN}(-7)$ & 0.1548 & -0.2600 & & & \\
\hline$p$-value & 0.6120 & 0.5813 & & & \\
\hline AIC & 1.1003 & 1.9696 & AIC & 0.5207 & 1.7758 \\
\hline $\mathrm{SC}$ & 1.7209 & 2.5902 & $\mathrm{SC}$ & 0.8821 & 2.1371 \\
\hline
\end{tabular}

Notes: This table presents the estimation results of our six kinds of bivariate-VECMs for the Japanese core CPI and other six CPIs in Japan. In this table, CORE denotes the CPI of all items excluding food for Japan; EG means the CPI of energy for Japan; INF denotes the CPI of telecommunication expenses for Japan; and HLTH denotes the CPI of insurance and medical expenses for Japan. Moreover, SERV represents the CPI of services for Japan; MIN denotes the CPI of industrial goods for Japan; and NDG means the CPI of nondurable goods for Japan. The samples are monthly and our analyzing sample period is from May 2011 to June 2015. Moreover, CE denotes the cointegrating equation, AIC means the Akaike's information criterion, and SC denotes the Schwartz information criterion. In addition, $* * *, * *$, and $*$ indicate the statistical significance of the coefficients in our models at the 1,5 , and $10 \%$ levels, respectively. 


\section{Empirical Results}

This section states our empirical results. In Table 2, the estimation results of our six types of VECMs are shown as follows. Namely, Panel A of Table 2 exhibits the results of the model of CORE and EG, Panel B displays the results of the model of CORE and INF, and Panel C shows those of CORE and HLTH. Further, Panel D exhibits the estimation results as to the model of CORE and SERV, Panel E shows those of CORE and MIN, and Panel F displays those of CORE and NDG. Table 2 demonstrates that all the coefficients $\lambda$ s in the CEs of all our six models are statistically significant with negative signs. In addition, in all our six models, the degrees of the statistical significance of the coefficients $\lambda s$ are very strong. Hence these empirical results suggest that our six combinations of the Japanese CPI series employed in this study are all much strongly cointegrated. These results therefore demonstrate that in order to capture the time-series connections of the Japanese CPIs, the VECM approach is significantly effective.

Moreover, for testing the effects of the CPIs of energy, telecommunication expenses, insurance and medical expenses, services, industrial goods, and nondurable goods for Japan on the core CPI of Japan, we obtain the impulse response functions from the VECMs. We show the impulses of the core CPI to other six Japanese CPIs in Figure 2. Specifically, Panel A of Figure 2 shows the impulse response of CORE to EG, Panel B displays the response of CORE to INF, and Panel C presents that of CORE to HLTH. Further, Panel D exhibits the response of CORE to SERV, Panel E shows that of CORE to MIN, and Panel F presents that of CORE to NDG, From the results shown in Figure 2, as far as judging by the impulse responses, it is understood that, for our analyzing period, the positive effects of the Japanese CPI of energy (Panel A), telecommunication expenses (Panel B), and industrial goods (Panel E) on the Japanese core CPI are weak. In addition, the core CPI for Japan is little affected by the Japanese CPI of insurance and medical expenses (Panel C). On the other hand, Figure 2 also demonstrates that according to our analyses of impulse responses, the Japanese core CPI is largely affected by both the Japanese CPIs of services (Panel D) and nondurable goods (Panel F).

Panel A. Response of CORE to EG

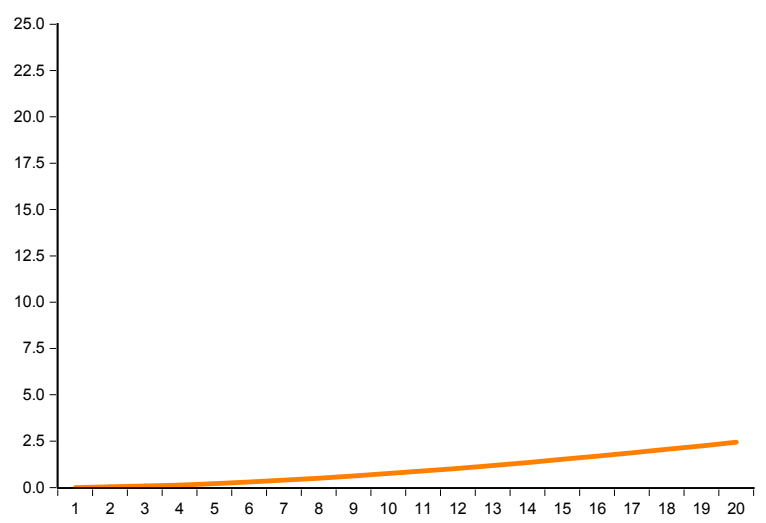

Panel C. Response of CORE to HLTH

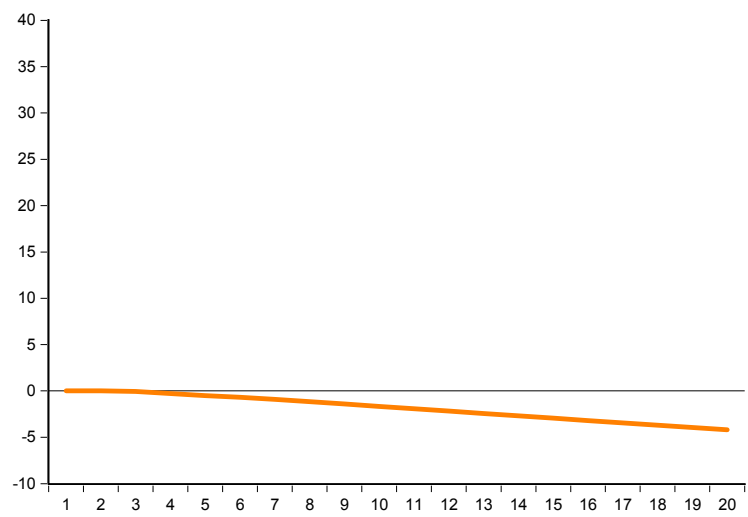

Panel B. Response of CORE to INF

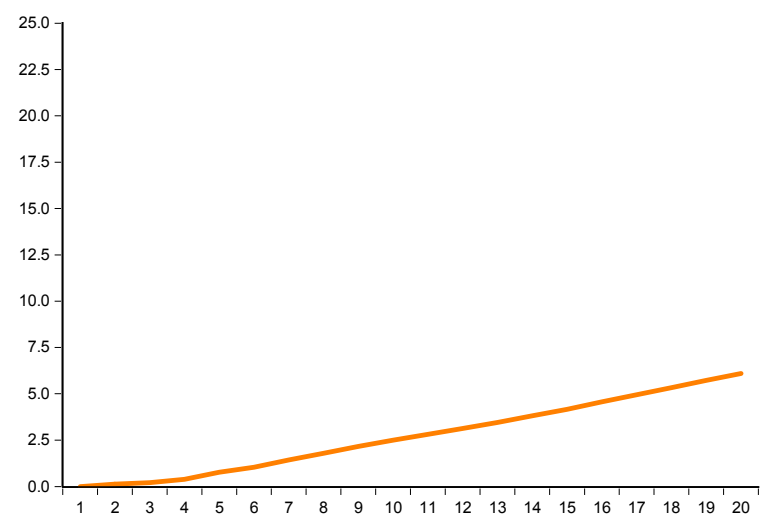

Panel D. Response of CORE to SERV

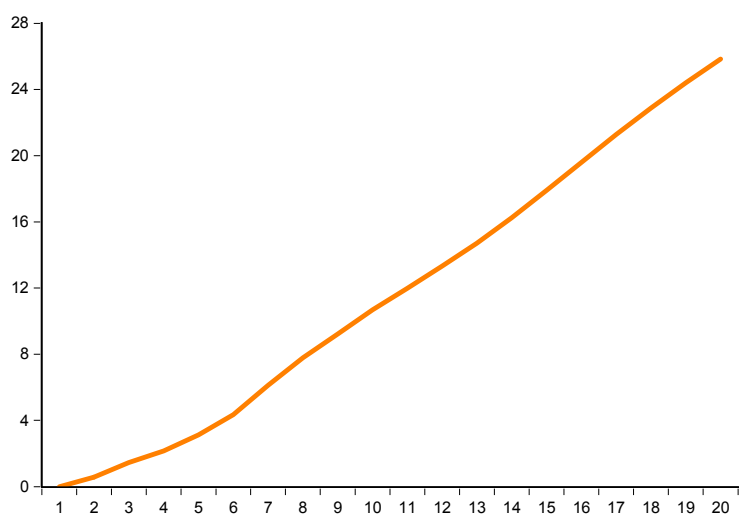


Panel E. Response of CORE to MIN

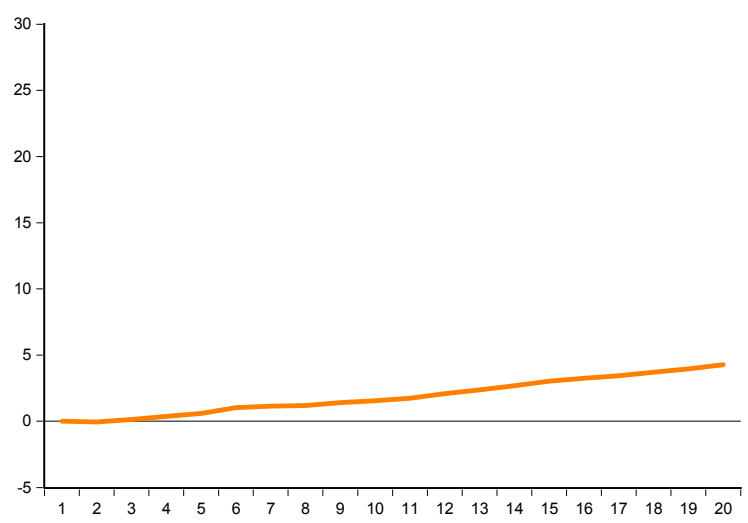

Panel F. Response of CORE to NDG

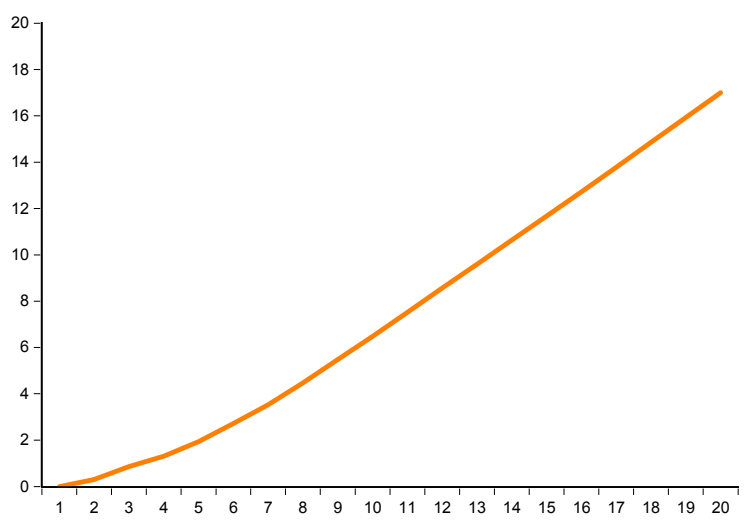

Figure 2. Responses of the Japanese core CPI to the CPIs of energy, telecommunication expenses, insurance and medical expenses, services, industrial goods, and nondurable goods for Japan

\section{Interpretations and Conclusions}

This paper tested the time-series linkages of several CPIs in Japan by using the VECM approach. Our empirical tests demonstrated the interesting findings as follows. First, we clarified that 1) all the cointegrating equations of our six VECM models were statistically significantly estimated. Hence these empirical results showed that our six combinations of the time-series of the Japanese CPIs examined in this study were all much strongly cointegrated. These results therefore showed that for capturing the time-series connections of the Japanese CPIs, our VECM approach was significantly effective.

Further, we also revealed that 1) as far as judging by the results of our impulse response analyses, it is understood that, in our analyzing sample period, the Japanese core CPI was not so strongly influenced by the Japanese CPI of energy, telecommunication expenses, insurance and medical expenses, or industrial goods. We also demonstrated that 2) our analyses of impulse responses suggested that the Japanese core CPI was largely affected by both the Japanese CPIs of services and nondurable goods.

In Japan, the Bank of Japan is currently executing the quantitative and qualitative easing (QQE) monetary policy in order to pull out of deflation; thus currently, the Japanese policy makers and central bankers are paying much attention to the trends of the Japanese core CPI. As our results indicate, it is important that the consumer prices which largely affect the core CPI for Japan shall be kept in a little higher suitable level for the Japanese economy according to the suggestions by the Bank of Japan. For this, important consumer prices for the core CPI of Japan should increase a bit more. The continuous efforts of government policy makers and central bankers in Japan are expected to produce the environment in which Japanese corporations can easily raise the prices of their items for sale. In this context, it is considered that the findings and implications from our VECM applications exhibited in this paper may be useful and informative.

In this paper, we investigated the six Japanese categorized CPIs with the core CPI in Japan as demonstrated above, thus our scope is limited to the dynamic relations of these price series employed in this paper. Hence further extended empirical research, for example by expanding the data set, may be interesting and informative. Thus this line of research shall be one of our future works.

\section{Acknowledgements}

I am particularly grateful to the kind repeated invitation from the journal to write to this journal. In addition, I appreciate the Zengin Foundation for Studies on Economics and Finance for their grant-in-aid to this research. Furthermore, I am also grateful to the Japan Society for the Promotion of Science for their generous financial assistance to my research. Finally, I deeply thank the Editors of this journal and Gina Perry for their kindness to this paper. 


\section{References}

Arora, V., Gomis-Porqueras, P., \& Shi, S. (2013). The divergence between core and headline inflation: Implications for consumers' inflation expectations. Journal of Macroeconomics, 38, 497-504. http://dx.doi.org/10.1016/j.jmacro.2013.07.006

Bodenstein, M., Erceg, C, J., \& Guerrieri, L. (2008). Optimal monetary policy with distinct core and headline inflation rates. Journal of Monetary Economics, 55, S18-S33. http://dx.doi.org/10.1016/j.jmoneco.2008.07.010

Bullard, J. (2011). Measuring inflation: The core is rotten. Federal Reserve Bank of St. Louis, 93, 223-233.

Johansen, S. (1991). Estimation and hypothesis testing of cointegration vectors in gaussian vector autoregressive models. Econometrica, 59, 1551-1580. http://dx.doi.org/10.2307/2938278

Johansen, S. (1995). Likelihood-based Inference in cointegrated vector autoregressive models. Oxford: Oxford University Press.

Juselius, K. (1992). Domestic and foreign effects on prices in an open economy: The case of Denmark. Journal of Policy Modeling, 14, 401-428. http://dx.doi.org/10.1016/0161-8938(92)90014-4

Manzan, S., \& Zerom, D. (2013). Are macroeconomic variables useful for forecasting the distribution of U.S. inflation? International Journal of Forecasting, 29, 469-478. http://dx.doi.org/10.1016/j.ijforecast.2013.01.005

Stock, J. H., \& Watson, M. W. (2007). Why has U.S. inflation become harder to forecast? Journal of Money, Credit and Banking, 39, 3-33. http://dx.doi.org/10.1111/j.1538-4616.2007.00014.x 